\title{
The Physical Condition in the Physical-Motor Disability, Case of Studies in Elementary Schools
}

\author{
Daniela Milagros Palacio González ${ }^{1}$, Sara González Santos ${ }^{2}$, Lirian Ruiz Reyes ${ }^{2}$, \\ Alberto Bautista Sánchez Oms ${ }^{1}$ \\ ${ }^{1}$ Faculty of Physical Culture, Central University "Marta Abreu" of Las Villas, Villa Clara, Cuba \\ ${ }^{2}$ Municipal University Center, Central University "Marta Abreu" of Las Villas, Villa Clara, Cuba
}

Email address:

dpalacio@uclv.cu (D. M. P. Gonzalez),sgsantos@uclv.cu (S. G. Santos), lirianr@uclv.cu (L. R. Reyes), asoms@uclv.cu (A. B. S. Oms)

\section{To cite this article:}

Daniela Milagros Palacio González, Sara González Santos, Lirian Ruiz Reyes, Alberto Bautista Sánchez Oms. The Physical Condition in the Physical-Motor Disability, Case of Studies in Elementary Schools. American Journal of Sports Science. Vol. 9, No. 2, 2021 , pp. 32-36. doi: 10.11648/j.ajss.20210902.11

Received: April 16, 2021; Accepted: May 7, 2021; Published: May 14, 2021

\begin{abstract}
The research presented is based on the need to apply the contents related to the subject Physical Activity Adapted to Inclusive Physical Education in a coherent and understandable way, offering the possibility of knowing what to do at each moment of the practice of physical activities aimed at children with Special Educational Needs (SEN). A work algorithm is designed based on the determination of the general objective related to the diagnosis of the state of the physical condition indicators in the schoolchildren taken as a sample. It works with a population of three schoolchildren with physical motor disabilities, belonging to the José Marti primary school in the Caibarién municipality. From the methodological point of view, theoretical and empirical methods are used, within the latter the case study as a general methodology to present the results of methods such as: documentary analysis, interview and measurement. As a result, the measurement of anthropometric indicators of physical efficiency is obtained: speed, flexibility and leg strength, as well as laterality, balance and spatial orientation, these are described and analyzed to enrich the comprehensive pedagogical diagnosis of schoolchildren and facilitate their inclusion in the Physical Education class, the precision of said indicators that respond to the specific situations of each case is achieved, in order to pay special attention to working with diversity, showing that the schoolchildren with (SEN) taken as a sample In research, they can be included in the Physical Education classes of the grade, based on respect for differences.
\end{abstract}

Keywords: Physical Condition, Diversity, Inclusive Physical Education

\section{Introduction}

In various national and international scientific exchanges, in the educational field, the problem of the inclusion of children, adolescents and young people with SEN has been analyzed in depth, among them we can mention: Universal Declaration of Human Rights [11]; Declaration of the Rights of the Child [12]; Warnock Report [24]; Salamanca World Conference UNESCO [25]; Events of the Latin American Center for Special Education, CELAEE [8], Urquiza \& García [26], among others.

Of these spaces, authors such as Acedo \& Opertti [1], Blanco, \& Duk [3], Infante [18], have taken up central ideas, to defend the educational integration and inclusion of schoolchildren with SEN, as a guarantee of equity, equality and respect, not only in the educational system but in all the processes of society, so that each one receives its benefits in the settings that best suit their needs and potential and the real possibilities of the contexts in which they live. Aiscow, [2].

Cuba reaffirms the position that educational inclusion is not at odds with the type of school that offers the educational offer, and it is related to the quality of education that is provided in any institution Orosco [20]. In recent years there have been profound changes in the development and conformation of a new dimension of education in Cuba, identified, more than with teaching, with a policy oriented 
towards full inclusion, respect and solidarity.

Carpio [9] refers to the following characteristics of educational inclusion:

a. The construction of an educational community is key in community and sociocultural models.

b. The philosophy and principle of these schools is "we" understood as a community.

c. Flexible schools in their curricula, evaluation, promotion and organization.

d. Focused on the characteristics of the student not on the content, facilitating the diversity of teaching and learning experiences.

e. Promulgates the values of humanization, freedom, criteria of normalization, democracy and justice.

f. Importance is given to the participation of parents in school activities, in supporting learning and in monitoring student progress.

g. It insists on an active participation by all, which goes beyond their presence.

h. It is assumed that all students belong to the group and all can learn in normal life, in school and in the community.

i. Attention to the diversity of interests, capacities, needs and potentials of all students, whether or not they have an intellectual, sensory or physical-motor SEN.

According to Castro [10], Borges [7], SEN of a physical motor nature are those considered by people who have a temporary or permanent deterioration in the osteomyoarticular and / or nervous system, which limits the performance of gross motor acts and fine that generate a set of different educational needs, as they are limited to carrying out activities that other contemporaries can carry out without requiring special aid. Castro [10] states that: "The person suffers a physical-motor disability when he has a partial or total loss, temporary or permanent, of any of his motor functions and / or his physical integrity."

The World Health Organization (WHO) [19] defines physical condition as integral corporal, mental and social well-being, which assumes a set of factors, capacities or qualities that the subject possesses as potential energy and that through its development allow obtaining a good level of physical fitness to carry out tasks of a physical-sporting nature. Its purpose is, therefore, of the "hygienic" type (health prevention) and is oriented towards normal activity.

The main theoretical and methodological aspects found in the reviewed bibliography, in relation to the process of attention to physical condition appear in investigative works by Fonseca [13]; Hasg and Dassel [17] and Álvarez [4]; Sicilia \& Ruiz [22]; Ruiz; Linaza \& Peñaloza [23]; Baena; Graner; Ruiz. [6]; They have referred to physical condition in terms of physical development, to its phases as a process, to the indicators to be evaluated.

Also, Arnaiz, [5]; Gomendio, [15]: González [16]; Garcés [14], Baena, Granero and Ruiz. [6], POMEF-INDER [21], state that the area of Physical Education and the practice of physical and sports activity are directly related to the physical condition of the students, to such an extent that this performance at an educational level will depend on it. For this reason, it is essential that the teacher knows the particularities of the physical condition, in order to correctly plan their teaching, coinciding with these approaches, the authors of the research

\section{Materials and Methods}

\section{Population}

The cases under study are three schoolchildren aged six and seven, two male, one female, attending the first and second grade (case 3) at the José Martí school in the Caibarién municipality, presenting Brachial Palsy of obstetric etiology case 1 and 2), with involvement of the right side. And Congenital Hip Dislocation (case 3).

From a dialectical-materialist approach, this research uses Case Studies, with the combination of qualitative and quantitative methods, to achieve a more complete and comprehensive analysis of the objective reality of the research object: the physical condition of the schoolchild.

Tabla 1. List of dimensions and indicators of the physical condition to be evaluated.

\begin{tabular}{lll}
\hline Dimensions & Indicators & Test \\
\hline \multirow{3}{*}{ Conditional physical abilities } & Flexibility test & Flexibility test. Garcés (2005) \\
& Quick test & Test for quick reaction and agility. Garcés (2005) \\
& Arm strength & Arm muscle strength test. Garcés (2005) \\
Coordination & Manual eye coordination & Test for manual and pedal eye coordination Garcés (2005) \\
& Pedial oculus coordination & \\
Spatial orientation & Forward - backward Spatial & Spatial orientation test. Garcés (2005) \\
\hline
\end{tabular}

\section{Result and Discussion}

\subsection{Analysis of the Applied Methods}

As a result of reviewing the personal documents of the cases, it was found that there is a psychopedagogical characterization of the 3 schoolchildren, but this does not include all the necessary data on physical development;
However, it states that from the intellectual point of view they present normal intelligence; although they present some language disorders. Regarding the physical condition in this document, only reference is made to height and weight in a general evaluative way. The three cases are categorized as students exempted from PE classes.

In the teacher's lesson plan; There are no individualized activities for differentiated attention to these, nor are the 
details and suggestions regarding the treatment of schoolchildren with physical-motor limitations in primary school taken into account.

In the interview carried out with the Physical Education teacher of the degree in the school with more than five years of experience in the work, she refers to not having experience in the care of physical motor disability, but if she thinks that it is very important to know the type of disability they have, as well as the treatment indicated by specialists.

In the interview with the mothers, they reported that the first symptoms of disability were varied, such as loss of movement of the arm and right hand, decreased ability to grip the affected side, abnormal position of the arm when flexing the elbow or he leaned it against his body. Two did not refer to a family history of physical motor disability. They care about the education of their children and comply with the guidelines of the school.

\subsection{Presentation of the Evaluation of the Physical Condition of Each Case}

\subsubsection{Case 1}

Six-year-old male schoolboy, in the first grade at the José Martí school in the Caibarién municipality, presents with Brachial Palsy of obstetric etiology, with involvement of the right side. Physical-motor disability of a neurological nature, this is defined as paralysis of the arm of variable degree, caused by a brachial plexus injury. The brachial plexus is the nerve structure located at the base of the neck and the axillary hollow, responsible for the muscular and cutaneous innervation of the thoracic limb. It is located approximately by the neck, armpit and arm.

Regarding the physical conditions measured, the result of the flexibility test showed that the student achieved a reach of $18 \mathrm{~cm}$ in the first attempt; $20 \mathrm{~cm}$ in the second and $22 \mathrm{~cm}$ in the third. The greater distance reached gave him an evaluation of good.

In the evaluation of speed and agility he achieved a time of 10 seconds for an evaluation of regular according to the Garcés 2005 scale.

As a result of the arm strength test in the first attempt, the throw executed by the schoolboy reached 1 meter of distance; in the second $1.3 \mathrm{~m}$ and in the third the ball reached $1.4 \mathrm{~m}$. with the right hand. While with the left the first throw reached 2 meters of distance; in the second $2.4 \mathrm{~m}$ and in the third the ball reached $2.5 \mathrm{~m}$. The longest shot turned out to be the latter, so if we consider his age, the evaluation is fine. In this indicator, there are consequences of disability such as brachial plexus injuries that are accompanied by severe functional disorders in the area from the neck, to the arm, and its terminal nerves. Therefore, the strength of the muscles in the neck and shoulder region is limited; despite this, the evaluation was satisfactory.

In the manual eye coordination test, the student achieved four throws with his left hand, for a total of four points; Successful throws with the right hand were three, to obtain seven points. The test was done in a short time, which gives it an evaluation of good. In the pedial eye coordination test, the student achieved two successful kicks between the lines with his left foot, for a total of three points; with the right foot three successful kicks also, to obtain three points, which gives him an evaluation of good. In the spatial orientation test, he managed to perform the steps to the front, back, to the right and to the left, also the two steps in front, he reflected independence and security to perform the two steps back, achieving a good evaluation with five points in total.

\subsubsection{Case 2}

Six-year-old male schoolboy, in the first grade at the José Martí School in the Caibarién municipality, presents a Brachial Palsy of obstetric etiology, with involvement of the left side. Physical-motor disability of a neurological nature, this is defined as paralysis of the arm of variable degree, caused by a brachial plexus injury. The brachial plexus is the nerve structure located at the base of the neck and the axillary hollow, responsible for the muscular and cutaneous innervation of the thoracic limb It is located approximately by the neck, armpit and arm.

Regarding the physical conditions measured, the result of the flexibility test showed that the student achieved a reach of $27 \mathrm{~cm}$ in the first attempt; $24 \mathrm{~cm}$ in the second and $25 \mathrm{~cm}$ in the third. The greater distance reached gave him an evaluation of good.

In the evaluation of speed and agility he achieved a time of 15 seconds for an evaluation of regular according to the Garcés [14] scale.

As a result of the arm strength test in the first attempt, the throw executed by the schoolboy reached 1 meter of distance; in the second $1.3 \mathrm{~m}$ and in the third the ball reached $1.3 \mathrm{~m}$ with the left hand, while with the right the first throw reached 1.7 meters; in the second $1.8 \mathrm{~m}$ and in the third the ball reached $2 \mathrm{~m}$. The longest throw turned out to be $2 \mathrm{~m}$, which allowed a good evaluation to be given.

In this indicator, there are consequences of disability such as brachial plexus injuries that are accompanied by severe functional disorders in the area from the neck to the left arm and its terminal nerves. Therefore, the strength of the muscles in the neck and shoulder region is limited; despite this, the evaluation can be described as satisfactory.

In the manual eye coordination test, the student achieved four throws with his right hand, for a total of four points; Successful throws with the left hand were two, to obtain six points according to the evaluative scale. The test was done in a short time, which gives it an evaluation of good.

In the oculus pedal coordination test, the student achieved three successful kicks between the lines with his right foot, for a total of three points; with his left foot two successful kicks as well, to obtain three points, which gives him an evaluation of good for achieving five points in total.

In the spatial orientation test, he managed to perform well the steps to the front, back, to the right and to the left, also the two steps in front, he reflected independence and security to perform the two steps back, managing to perform both. That gives you a total of 8 points for a good evaluation.

\subsubsection{Case 3}

A seven-year-old female student in the second grade at the José Martí school in the Caibarién municipality, presents 
Congenital Hip Dislocation (CCL); conceived as the malformation of the joint of the coccyx with the femoral; more frequent in girls than in boys, of osteoarticular origin, it can be unilateral or both parts affected, in the case that it presents it is left unilateral.

Regarding the physical conditions measured, the result of the flexibility test showed that the schoolgirl reached $22 \mathrm{~cm}$ in the first attempt; $25 \mathrm{~cm}$ in the second and $24 \mathrm{~cm}$ in the third. The greater distance reached allowed him to obtain an evaluation of good.

In the evaluation of speed and agility, he achieved a time of 12 seconds for an evaluation of good according to the 2006 Garcés scale. Taking into account the involvement of the left hip, there was incoordination in the movement of taking and placing the block, but achieved the set time.

As a result of the arm strength test in the first attempt, the throw reached $3 \mathrm{~m}$ distance; in the second $3.2 \mathrm{~m}$ and in the third the ball reached $3.57 \mathrm{~m}$. The longest shot was $3.57 \mathrm{~m}$, so she could evaluate herself well. In this indicator, the effectiveness of the result of it depended on the quality of movements involved in the throw and that allows the left hip joint to the school one, in this case the internal and external rotation, which have limitations; even so, the distance reached reflects adequate arm strength.

In the manual eye coordination test the schoolgirl achieved a successful throw with her left hand, for a total of one point; Successful throws with the right hand were three, to obtain three points, which gives him a bad evaluation, for generally obtaining four points in the test.

In the oculus pedal coordination test, the schoolgirl achieved two effective kicks between the lines with her left foot, for a total of two points; her with her right foot two successful kicks below the line, to obtain four points. The total of points in the test was six points, which gives him a fair evaluation. Taking into account that the hip involvement is located on the left side, she presented incoordination in the movement, but the value of effective kicks was always taken.

In the spatial orientation test, the schoolgirl managed to perform the steps to the front, back, to the right and to the left, also the two steps in front, but she reflected a lot of insecurity to perform the two steps back, only managing to perform one. That gives you a total of 7 points for a good evaluation. In the evaluation of this indicator, the difficulty in the motor area could influence, which is fundamentally in the left hip area, so the leg on the same side is of interest, however, this girl assimilates activities quickly and safely.

When evaluating the results of the applied tests, it can be stated that:

In general, in the result of the measurement of the physical condition indicators, arm strength and spatial orientation were the indicators that performed the best in the three cases. In case 3 , some adaptations were included, which did not prevent the schoolchild from expressing the real state of her disability.

\section{Conclusions}

1. The behavior of the indicators of physical condition evaluated in Case 1, showed a favorable state in the capacity of flexibility, speed, arm strength and spatial orientation; unlike the ability to coordinate, essentially the manual eye.

2. Case 2 showed better results in the evaluation of the indicators, only in the speed the behavior was regular, this places it as the case of better physical conditions, according to the data obtained.

3. The physical condition in Case 3 behaved more unfavorable, especially in the flexibility, speed, coordination indicators, despite the adaptations made; Pediatric ocular coordination could be conditioned by the paresis of the lower limbs, resulting from his state of paraplegia.

4. In general, the physical condition of the investigated cases showed better performance in the indicators of arm strength, spatial orientation, and flexibility; not so in the coordination in its two variants.

\section{References}

[1] Acedo, C., \& Opertti, R. (2012). Inclusive Education: from targeting groups and schools to achieving quality education as the heart of Education for All (EFA). Education for All in Latin America. Studies on inequalities and the political agenda in education.

[2] Aiscow, M. (2005). The next challenge: improving the inclusive school. In Congress, Effectiveness and School Improvement, (p. 20). Barcelona.

[3] Blanco, R., \& Duk, C. (2019). Conmemoración de la Conferencia Mundial de Salamanca y su Influencia en América Latina. Revista latinoamericana de educación inclusiva, 13 (2), 17-23.

[4] Álvarez Choren. I. (2001) Physical condition with field tests in the elderly. Rev. Galega de Actualidad Sanitaria. 2001; 1 (2): 90-93.

[5] Arnaiz, P. (1994). Psychomotor skills and curricular adaptations: Psychomotor skills. Journal of Studies and Experiences, 47: 10-15.

[6] Baena, A.; Granero, A.; Ruiz, P. J. (2010). Components for the evaluation of physical condition.

[7] Borges, S. (2006). Education of students with special educational needs. Fundamentals and current affairs, Ed. Pueblo y Educación, La Habana.

[8] CELAEE (2013). Solidarity with Panama Special School. Cuban experience in comprehensive care for children with physical-motor disabilities. Study material. Master of Special Education. Havana: Cuba.

[9] Carpio, T. (2017). Educational inclusion contemporary approaches to disability.

[10] Castro, P. L. (2007) School educational attention with motor impairments in the classroom. DFM.

[11] Human Rights, D. U. of (1948). Universal Declaration of Human Rights. United Nations General Assembly, 10. 
[12] Del Niño, D. D. L. D. (1959). Declaration of the Rights of the Child (Vol. 2). Recovered.

[13] Fonseca, V. (1988). The components and levels of physical condition in schoolchildren. Editorial INDE. Spain.

[14] Garcés, J. (2006). Proposal of tests to evaluate motor skills in children with mental retardation.

[15] Gomendio, Margarita (2000): "Physical education for the integration of children with special educational needs. Physical activity program for children from 6 to 12 years old. Madrid, Editorial Gymnos.

[16] González, E. (2004). Reflections on Education in children with SEN. Mimeographed material.

[17] Hasg, H. and Dassel, H. (1995) Physical Condition. In the School field and Sports Initiation. Editorial Hispano Europea, S. A. Barcelona Spain.

[18] Infante, M. (2010). Challenges to teacher training: educational inclusion. Pedagogical Studies, 36 (1), 287-297. Chile. Recovered from http://www.scielo.cl/scielo.php?pid=S071807052010000100016\&script $=$ sci_arttext

[19] WHO, (1992). Physical condition and health. Office of the World Health Organization. Geneva.

[20] Orosco, M. (2014). Educational inclusion and special education. A unique and diverse horizon to match development opportunities. Havana: Cuban Education Editor Seal.

[21] POMEF-INDER (2016). Programs and Methodological Orientations of Physical Education in primary education. Edit Town and Education. Havana Cuba.

[22] Sicilia, A. O., \& Guerrero, A. B. Evaluation and control strategies of physical condition indicators. Paidotribo. Faculty of Physical Activity and Sports Sciences University of Granada.

[23] Ruiz Pérez, L. M., Linaza Iglesias, J. L., \& Peñaloza Mendes, R. (2008). The study of motor development: between tradition and the future. Fuentes Magazine, 8, 243-258.

[24] Warnock, M. (1978). Warnock report. Pedagogy Notebooks, (197).

[25] UNESCO (1994). Salamanca World Conference, Blanco, R., \& Duk, C. (2019). Commemoration of the Salamanca World Conference and its Influence in Latin America. Latin American Journal of Inclusive Education, 13 (2), 17-23.

[26] Urquiza, M. F., \& García, C. (2019). La inclusión educativa en escuelas primarias de sectores populares del Gran Mendoza. In XIII Jornadas de Sociología. Facultad de Ciencias Sociales, Universidad de Buenos Aires. 